\title{
Management of Irritational Fibroma of the Tongue with Diode Laser: A Case Report
}

\author{
Akhil K Padmanabhan*, Esha Yadav, Richa S Gautam and Prabhuji MLV \\ Department of Periodontology, Krishnadevaraya College of Dental Sciences and Hospital, India
}

*Corresponding author: Akhil K Padmanabhan, Department of Periodontology, Krishnadevaraya College of Dental Sciences and Hospital, India

\begin{abstract}
Irritational fibroma is a common presentation on the lateral surfaces of the tongue due to irregular and sharp surfaces of the dentition. It is a reactive lesion and is benign in nature. Irritational fibroma is well managed with conventional scalpel excision techniques. Of all the techniques mentioned for excision of the lesion, laser is found to produce the best results in terms of intraoperative bleeding, recurrence, scar formation and patient comfort. This case report presents the management of irritational fibroma in a middle aged female patient with diode laser.
\end{abstract}

\section{Introduction}

Fibroma is a common benign lesion of the oral cavity. It is often seen on the tongue, lips and some parts of the keratinized mucosa. They are painless and often do not cause any discomfort. However they can interfere with functions such as chewing and talking and hence some patients prefer to get them removed. Histologically, Irritational fibroma demonstrates a reactive focal fibrous hyperplasia due to local irritation [1,2]. The common irritational factors are plaque, calculus, overhanging margins and restorations $[3,4]$. This case report describes a case of irritational fibroma treated with diode laser in a middle aged female patient.

\section{Case Report}

The patient visited our outpatient department for routine dental examination. On clinical examination, a solitary nodular lesion, firm to soft in consistency, with no erythema or surface irregularities was noted on the left lateral surface of the tongue (Figure 1). Patient did not complain of any pain or discomfort on palpation. On extra oral examination, no lymphadenopathy or signs of infection were noted. Hard tissue examination revealed sharp lingual cusps of mandibular posterior teeth. Based on the findings, a provisional diagnosis of irritational fibroma was made. Patient was

advised for complete blood investigations and an appointment was scheduled for the excision. Patient opted for laser excision while all the treatment options were explained to her. On the day of excision, the systemic health of the patient was reassured. An airotor with a straight fissure bur was used to regularize the sharp cusps to avoid further irritation to the soft tissues during mastication (Figure 2). After odontoplasty, local anesthetic gel (Lidocaine Hydrochloride 2 $\%$ ) was applied over the area including the area surrounding the lesion. Local anesthetic infiltration was given surrounding the lesion. A FOX A.R.CTM, Diode laser was used for excision. The laser settings were continuous wave (CW) mode, $2.5 \mathrm{~mW}$ (Power) and a 400 micron cutting fiber for excision. The tongue was immobilized by holding the tip with a dry gauze. The lesion was stabilized with a micro hemostat (Figure 3) and the laser tip was activated to excise the lesion from the posterior to anterior aspect of the tongue (Figure 4). The lesion was excised and sent for histological analysis. Throughout the procedure which took around fifteen minutes, the patient did not complain of any pain or discomfort. She was discharged after the procedure and analgesics were prescribed to be taken if necessary. On three months follow up, the area had healed completely with no scar (Figure 5). 


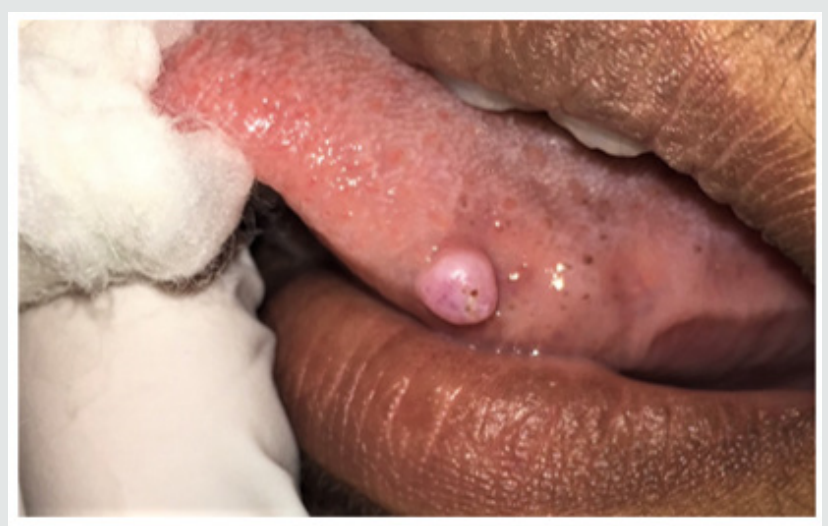

Figure 1: Fibroma on the left lateral side of lip.

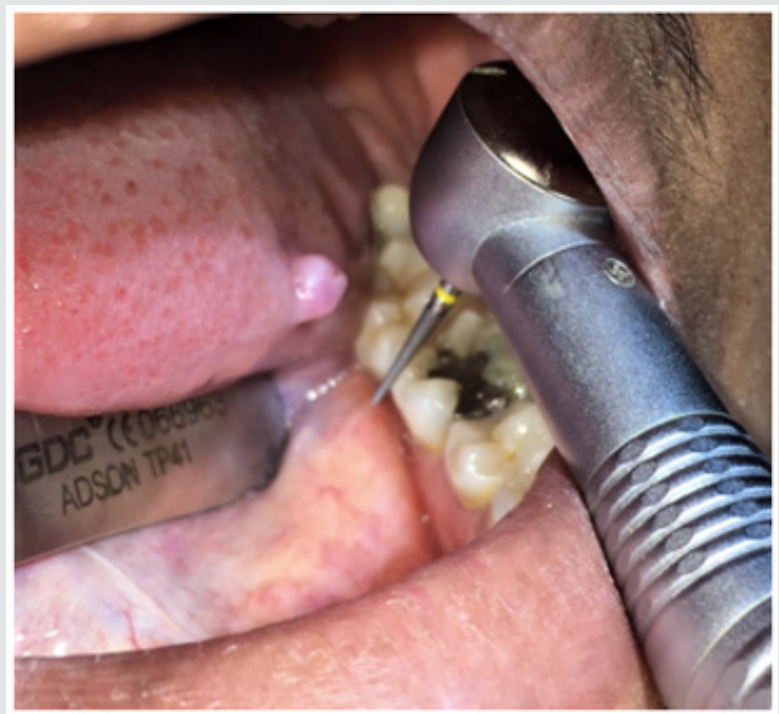

Figure 2: Odontoplasty to remove irregularities.

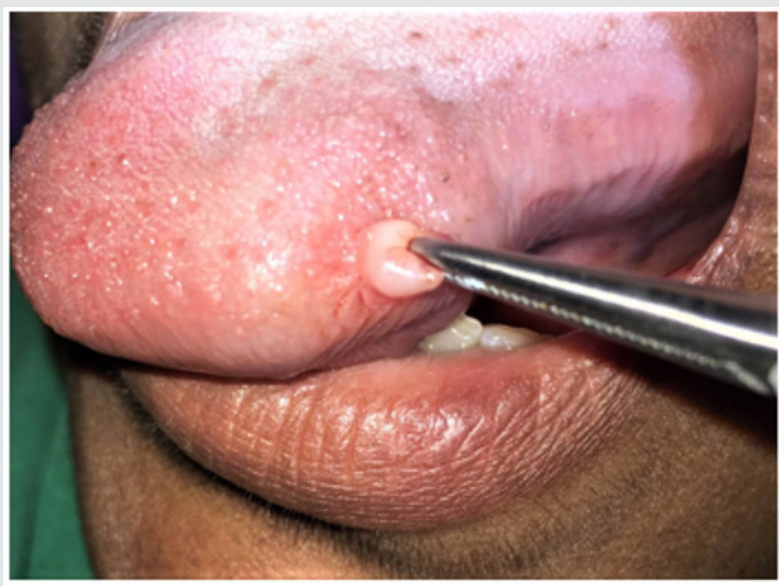

Figure 3: The lesion held with hemostat.

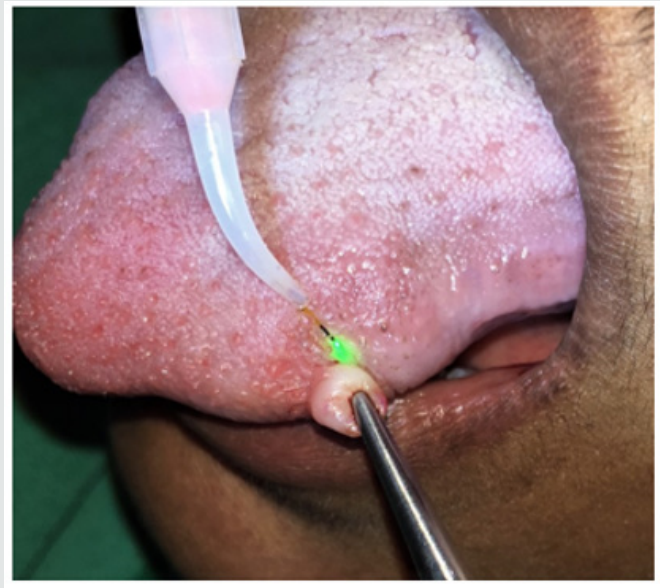

Figure 4: Excising the lesion with diode laser.

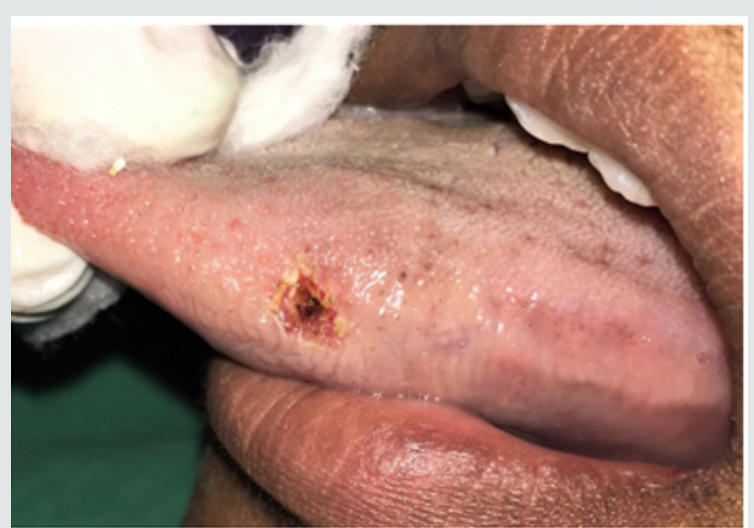

Figure 5: The surgical area after excision.

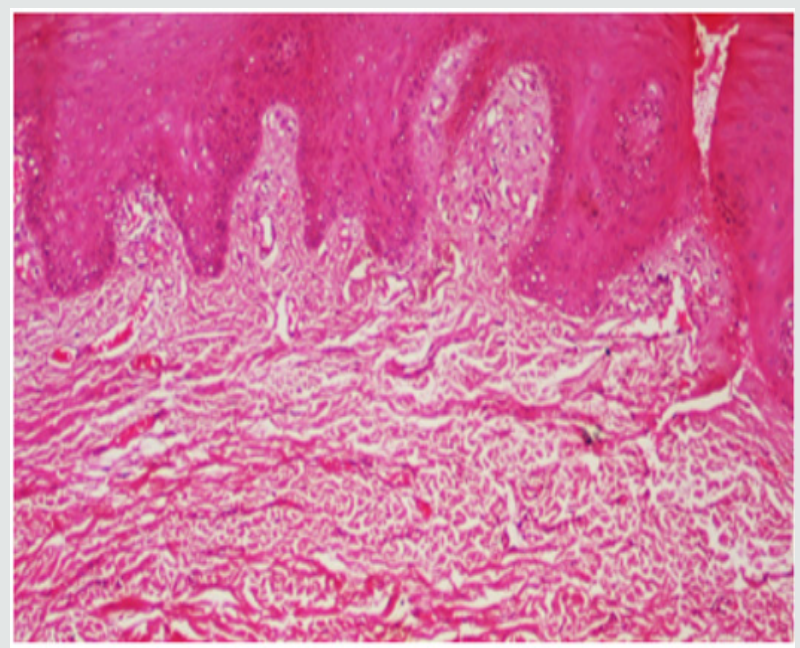

Figure 6: Histological view $(20 \mathrm{X})$ of the excised lesion showing hyper keratinization and nodular mass composed of collagenized fibrous connective tissue. 


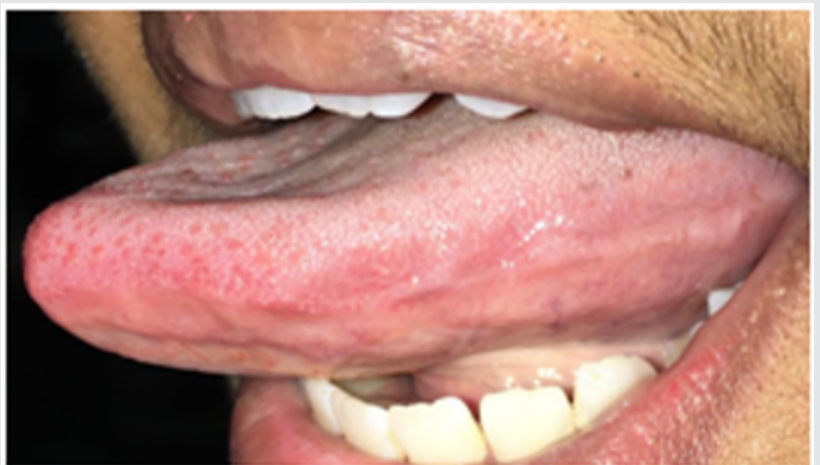

Figure 7: Three months postoperative view showing healed wound with no scar.

\section{Discussion}

This case report describes a case of irritational fibroma of the tongue which was treated with a diode laser. The histological analysis showed nodular mass composed of collagenase fibrous connective tissue which confirmed the diagnosis of an irritational fibroma (Figure 6). Irritational fibroma, otherwise known by different names such as focal fibrous hyperplasia or fibromatosis fibroma has a female predilection. Although uncommon, it often poses functional problems to few patients and hence requires treatment. Irritational fibroma is commonly seen in the maxilla than the mandible [5]. In this case, lesion was present in relation to the mandibular molar region. They usually measure less than 1.5 $\mathrm{cm}$ in diameter. The surface of lesion may be ulcerated in $66 \%$ of cases and intact in $34 \%$ of cases. In the present case diameter of the lesion was $0.8^{*} 0.7 \mathrm{~cm}$ in diameter. The lesion usually represents multiple stages of fibroma with ossification [6]. However, we did not note any ossifications in this case. The most common way of treating fibromas are by scalpel incisions, but in this case, laser was used to reduce the bleeding, reduce the post-operative pain and improve the healing with less scar formation [7]. The same was achieved in our case. Laser continues to be optimal in treating several oral lesions with increased patient acceptance and enhanced clinicians comfort. The patient did not complain of any post treatment pain and analgesics were not necessary. She was recalled after three months and the area had healed completely without any scar formation.

\section{Conclusion}

Irritational fibroma, although benign, can be quite disturbing to the patient and requires surgical excision. Diode laser excision is an effective method of excising fibroma form the patient as well as the clinician's perspective.

\section{References}

1. Jafarzadeh H, Sanatkhani M, Mohtasham N (2006) Oral pyogenic granuloma: a review. Journal of oral science 48(4): 167-175.

2. Baldawa R, Saluja H, Kasat V, Kalburge J, Baheti S (2011) An unusually large oral pregnancy tumor. Pravara Medical Review 3(4): 23-26.

3. Mathur LK, Bhalodi AP, Manohar B, Bhatia A, Rai N, et al. (2010) Focal fibrous hyperplasia: a case report. International Journal of Dental Clinics 2(4).

4. Nartey NO, Mosadomr HA, Al-Cailani M, Al-Mobeerik A (1994) Localized inflammatory hyperplasia of the oral cavity: clinico-pathological study of 164 cases. Saudi Dent J 6(3): 145-150.

5. Das U, Azher U (2009) Peripheral ossifying fibroma. Journal of Indian Society of Pedodontics and Preventive Dentistry 27(1): 49.

6. Bagde H (2012) Peripheral Cemento Ossifying Fibroma-Case Report. Int J Dent Case Reports 2(5): 15-18.

7. Levine R, Vitruk P (2014) Laser-Assisted Removal of Irritation Fibroma. Global Laser Oral Health.

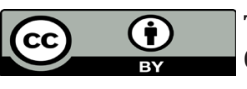

This work is licensed under Creative Commons Attribution 4.0 License

To Submit Your Article Click Here:

Submit Article
DOI: $10.32474 / \mathrm{SJ} 0.2020 .04 .000191$

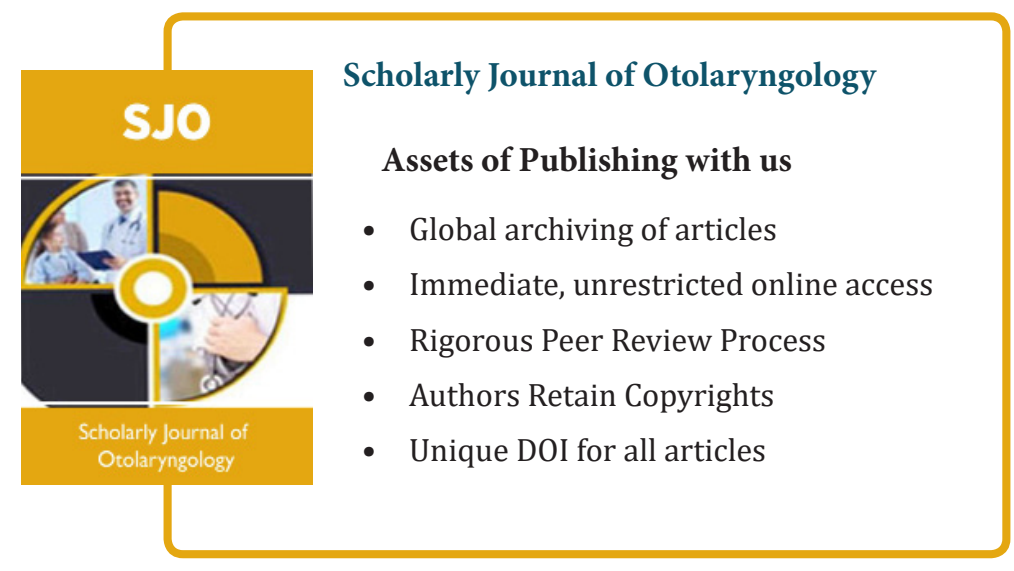

